\title{
Hubungan antara Motivasi Kerja, Kepuasan Kerja, dan Karakteristik Tenaga Kesehatan Aparatur Sipil Negara (ASN) terhadap Retensi Bekerja di Puskesmas: Analisis Data Risnakes 2017
}

\author{
Relationship between Work Motivation, Job Satisfaction and Characteristics of ASN Health \\ Workers to Work Retention in Puskesmas: Risnakes 2017 Data Analysis
}

Iin Nurlinawati*, Lelly Andayasari, dan Syachroni

Pusat Penelitian dan Pengembangan Sumber Daya dan Pelayanan Kesehatan, Badan Penelitian dan Pengembangan Kesehatan, Kementerian Kesehatan RI, Jln. Percetakan Negara No. 29 Jakarta Pusat, DKI Jakarta, 10560, Indonesia.

*Korespondensi Penulis: inurlinawati@gmail.com

Submitted: 15-01-2020, Revised: 22-05-2020, Accepted: 27-05-2020

DOI: https://doi.org/10.22435/mpk.v30i2.2674

\begin{abstract}
Abstrak
Masih terdapat kesenjangan kebutuhan tenaga kesehatan berdasarkan rasio jumlah penduduk Indonesia di tahun 2019. Salah satu rekomendasi kebijakan yang dikeluarkan oleh WHO menyebutkan bahwa perlu memaksimalkan retensi tenaga kesehatan di daerah perdesaan terutama yang kurang terlayani dengan pelayanan kesehatan. Selain itu juga sejalan dengan target 3.C pada SDG's yakni meningkatkan pembiayaan kesehatan dan rekrutmen, pengembangan, pelatihan dan retensi tenaga kesehatan. Studi terdahulu menyatakan bahwa sistem pelayanan kesehatan di perdesaan dan daerah terpencil dapat terlaksana dengan baik apabila motivasi dan retensi tenaga kesehatan meningkat sehingga tidak terjadi lagi migrasi tenaga kesehatan. Studi lain menunjukkan bahwa peningkatkan insentif dan kepuasan kerja merupakan upaya yang dapat dilakukan untuk mengatasi masalah retensi dokter di daerah. Penelitian ini bertujuan mengetahui hubungan motivasi kerja, kepuasan kerja, dan karakteristik tenaga kesehatan Aparatur Sipil Negara (ASN) terhadap retensi kerja di puskesmas. Studi ini merupakan hasil analisis lanjut dari data Riset Tenaga Kesehatan (Risnakes) tahun 2017 dengan sampel adalah seluruh tenaga kesehatan di puskesmas yang berstatus ASN. Data dianalisis secara univariat, bivariat, dan multivariat untuk melihat faktor apa yang paling berpengaruh. Berdasarkan hasil penelitian terdapat hubungan yang bermakna antara umur, jenis kelamin, tingkat pendidikan, status pernikahan, lama bekerja di puskesmas dan akses menuju tempat kerja, motivasi, dan kepuasan kerja dengan retensi atau kebetahan tenaga kesehatan ASN untuk terus bekerja di puskesmas $(p<0,05)$. Hasil analisis multivariat menunjukkan bahwa mudahnya akses menuju tempat kerja merupakan faktor dominan yang berhubungan dengan retensi kerja $(\mathrm{OR}=1,928 ; 95 \% \mathrm{Cl}: 1,848-2,011)$. Diharapkan pemerintah daerah dapat memberikan kemudahan akses menuju tempat kerja bagi tenaga kesehatan yang bekerja di puskesmas. Kebijakan pembangunan rumah dinas bagi tenaga kesehatan dapat menjadi satu solusi agar tenaga kesehatan betah bekerja di daerah.
\end{abstract}

Kata kunci: retensi; tenaga kesehatan; motivasi; kepuasan

\section{Abstract}

There is still a gap in the need for health workers based on the ratio of Indonesia's population in 2019. One of the policy recommendations issued by WHO states that it is necessary to maximize the retention 
of health workers in rural areas, especially those that are underserved by health services. It is also in line with the target 3.C of SDG's goals of increasing health financing and recruitment, development, training and retention of health workers. Previous studies state that the health service system in rural and remote areas can be implemented well if the motivation and retention of health workers increased so that there is no longer a migration of health workers. Another study shows that increasing incentives and job satisfaction is an effort that can be done to overcome the problem of doctor retention in the area. This study aimed to determine the relationship of work motivation, job satisfaction and characteristics of government officer (ASN) as health workers to work retention at the community health center (puskesmas). This study is the result of further analysis of Health Workforce Research (Risnakes) data in 2017 with a sample of all health workers in puskesmas with ASN status. Data were analyzed using univariate, bivariate and multivariate to see what factors most influencing. Based on the results of the study there was a significant relationship between age, sex, level of education, marital status, length of work at the puskesmas and access to the workplace, motivation and job satisfaction with the retention of the ASN health personnel to continue working at the puskesmas $(p<0.05)$. The results of multivariate analysis showed that easy access to the workplace was the dominant factor associated with work retention (OR = 1.928; 95\% Cl: 1.848-2.011). It is expected that local governments can provide easy access to the workplace for health workers who work at puskesmas. The policy to build official housing for health workers can be a solution so that health workers feel at home when working in the regions.

Keywords: retention; health workers; motivation; satisfaction

\section{PENDAHULUAN}

Pusat kesehatan masyarakat (puskesmas) menjadi unit pelaksana pelayanan kesehatan yang akan berhubungan langsung dengan pelayanan masyarakat di lapisan terdepan. Visi pembangunan kesehatan masyarakat yakni "masyarakat sehat mandiri dan berkeadilan", harus diwujudkan sehingga mampu menjangkau masyarakat secara adil dan merata. Fungsi utama puskesmas yakni menyelenggarakan upaya kesehatan preventif dan promotif, yang didukung upaya kuratif dan rehabilitatif, serta melakukan pemberdayaan masyarakat. Hasil yang diharapkan adalah puskesmas berfungsi dengan lebih baik sehingga mampu memberikan pelayanan yang bermutu bagi masyarakat yang membutuhkan.

Keberhasilan puskesmas dalam menjalankan program tentunya dipengaruhi oleh ketersediaan sumber daya manusia (SDM) dalam hal ini adalah Aparatur Sipil Negara (ASN) yang seimbang antara tenaga pengobatan dengan tenaga promotif dan preventif. Peran penting tenaga kesehatan dalam membangun ketahanan masyarakat dan sistem kesehatan berefek pada berfungsinya sistem kesehatan dengan baik sehingga meningkatkan cakupan layanan kesehatan. Kemajuan yang signifikan dalam sistem kesehatan dilakukan melalui peningkatan kemauan politik dan memobilisasi sumber daya sebagai bagian dari upaya yang lebih luas untuk memperkuat dan membiayai sistem kesehatan secara memadai. Upaya pengembangan tenaga kesehatan telah membuahkan hasil yang signifikan. Banyak negara yang telah berhasil mengatasi tantangan tenaga kesehatan mereka, yang berdampak pada meningkatnya capaian kesehatan masyarakat. ${ }^{1}$

Hingga saat ini masih banyak masalah yang dihadapi puskesmas terkait pengelolaan tenaga kesehatan diantaranya tentang distribusi SDM yang tidak merata dan retensi tenaga kesehatan. $^{2}$ Hal ini didukung oleh penelitian terdahulu yang menyatakan retensi tenaga kesehatan masih menjadi masalah di Indonesia terutama di daerah tertinggal, hal ini dapat dilihat dari 4 tema besar yaitu finansial insentif, 
dukungan personal dan profesional, pendidikan, dan regulasi. ${ }^{3}$ Perkiraan kebutuhan tenaga kesehatan berdasarkan rasio penduduk tahun 2019 adalah sebesar 482.113 orang di seluruh Indonesia, sementara itu tenaga kesehatan yang tersedia sebesar 437.721 orang sehingga terjadi kesenjangan kebutuhan tenaga kesehatan sebesar 23.337 orang. ${ }^{4}$ Salah satu rekomendasi kebijakan yang dikeluarkan oleh WHO menyebutkan bahwa perlu memaksimalkan retensi tenaga kesehatan terutama di daerah perdesaan dan yang kurang terlayani dengan pelayanan kesehatan. Selain itu juga sebagai bagian dari SDG's, pada target 3.C yakni meningkatkan pembiayaan kesehatan dan rekrutmen, pengembangan, pelatihan dan retensi tenaga kesehatan. ${ }^{1}$ Studi terdahulu menyatakan bahwa sistem pelayanan kesehatan di perdesaan dan daerah terpencil dapat terlaksana dengan baik apabila motivasi dan retensi tenaga kesehatan meningkat sehingga tidak terjadi lagi migrasi tenaga kesehatan. ${ }^{2}$ Labarda menambahkan peningkatkan insentif dan kepuasan kerja merupakan upaya yang dapat dilakukan untuk mengatasi masalah retensi dokter di Filipina. $^{5}$ Analisis lanjut data Riset Tenaga Kesehatan (Risnakes) 2017 ini bertujuan mengetahui apakah motivasi kerja, kepuasan kerja, dan karakteristik sosiodemografi mempunyai hubungan dengan retensi tenaga kesehatan ASN puskesmas di Indonesia.

\section{METODE}

Studi ini merupakan hasil analisis lanjut dari data Riset Tenaga Kesehatan (Risnakes) tahun 2017. ${ }^{6}$ Sampel adalah seluruh tenaga kesehatan di puskesmas yang berstatus ASN dan menandatangani informed consent. Pada Risnakes 2017, kuesioner penilaian motivasi dan kepuasan dilakukan dengan cara diisi sendiri oleh responden (self-administered) dan didampingi oleh enumerator.

Variabel dependen pada analisis lanjut data Risnakes 2017 ini ialah retensi kerja melalui pertanyaan "Apakah [NAMA] betah bertugas disini?" (blok V). Sedangkan variabel independen yang diteliti meliputi data blok III mengenai umur, jenis kelamin, tingkat pendidikan, jenis tenaga kesehatan, status pernikahan, lama bekerja di puskesmas saat ini; data blok VI mengenai persepsi akses menuju lokasi tempat kerja, serta data blok VII terkait motivasi kerja dan kepuasan kerja. Pertanyaan motivasi kerja pada instrumen Risnakes terdiri dari 7 konstruk yang terdiri dari 23 pernyataan. Ketujuh konstruk tersebut terdiri dari motivasi secara umum (3 pernyataan), kelelahan emosional (2 pernyataan), kepuasan kerja ekstrinsik (3 pernyataan), kepuasan kerja intrinsik (3 pernyataan), komitmen organisasi (5 pernyataan), kesungguhan dalam bekerja (4 pernyataan), dan ketepatan waktu (3 pernyataan). Pilihan persetujuan terhadap pernyataan dibuat dalam skala Likert 1-5 (1=sangat tidak setuju, $2=$ tidak setuju, $3=$ kurang setuju, $4=$ setuju, $5=$ sangat setuju). Kode tersebut akan diterapkan terbalik terhadap pernyataan negatif. Pernyataan negatif terdapat pada pernyataan nomor $2,4,5$, $7,11,15,17,22$, dan 23. Penilaian kepuasan kerja mengacu pada instrumen Minnesota Satisfaction Questionnaire (short form) yang terdiri dari 20 skala yaitu: kemampuan (ability utilization), pencapaian (achievement), kegiatan (activity), kemungkinan pengembangan diri (advancement), wewenang (authority), kebijakan institusi (company policies), pendapatan (compensation), interaksi dengan rekan kerja (coworkers), kreativitas (creativity), kemandirian (independence), kemapanan/keamanan (security), kesempatan untuk melakukan hal bermanfaat untuk orang lain (social service), status sosial (social status), nilai-nilai moral (moral values), pengakuan (recognition), tanggung jawab (responsibility), supervisi/pengawasan (supervision-human relation), pengawasan secara teknis (supervision-technical), variasi/ keberagaman (variety) dan kondisi/lingkungan kerja (working conditions). Pernyataanpernyataan tersebut dikelompokkan menjadi 3 dimensi yaitu kepuasan intrinsik (pernyataan $1,2,3,4,7,8,9,10,11,15,16,20)$, kepuasan ekstrinsik (pernyataan 5, 6, 12, 13, 14, 19), dan kepuasan secara umum (seluruh pernyataan). Pilihan tingkat kepuasan terhadap pernyataan 
dibuat dalam skala Likert $1-5 \quad(1=$ sangat tidak puas, $2=$ tidak puas, $3=$ biasa saja, $4=$ puas, $5=$ sangat puas).

Analisis data dilakukan secara univariat untuk mengetahui distribusi frekuensi dari masing-masing variabel. Kategori umur tenaga kesehatan ASN dibagi menjadi dua kategori, yaitu $<38$ tahun dan $\geq 38$ tahun. Status pernikahan dibagi menjadi 3 kategori, yaitu belum menikah, menikah, dan cerai (cerai hidup dan cerai mati). Pendidikan tenaga kesehatan dibagi menjadi 2 kategori, yaitu rendah (DIII) dan tinggi (S1, S2, spesialis, dan S3). Lama kerja di puskesmas saat ini dibagi menjadi 2 kategori yaitu $\leq 8$ tahun dan $>8$ tahun. Akses menuju lokasi tempat kerja dibagi menjadi 2 kategori, yaitu sulit (sangat sulit, sulit) dan mudah (sangat mudah, mudah). Sesuai dengan pedoman Risnakes, peneliti melakukan analisis data terkait tingkat motivasi dan kepuasan dengan cara menjumlahkan skor tiap dimensi dari skor masing-masing pernyataan terkait. Skor tiap dimensi kemudian dikonversi ke dalam skala 100 agar antar subskor setiap konstruk dapat dibandingkan dan dikategorikan menurut persentil. Persentil $\leq 25$ dikategorikan ke dalam tingkat rendah, persentil 26-74 tingkat sedang, dan persentil $\geq 75$ tingkat tinggi.

Uji statistik antara variabel dependen dengan independen dilakukan dengan analisis bivariat dan diakhiri dengan analisis multivariat. Analisis bivariat menggunakan uji Pearson ChiSquare, variabel yang mempunyai nilai $p<0,25$ pada analisis bivariat dimasukkan sebagai model dalam analisis multivariat. Sementara itu pada analisis multivariat menggunakan uji regresi logistik ganda dengan metode Enter.

\section{HASIL}

Jumlah seluruh data yang dianalisis adalah sebesar 130.931 responden. Berdasarkan penelitian memperlihatkan bahwa mayoritas responden berumur $<38$ tahun (52,12\%), berjenis kelamin perempuan $(82,92 \%)$, dan menikah (91,29\%). Pendidikan tenaga kesehatan ASN di puskesmas mayoritas berada pada tingkat pendidikan diploma III $(61,57 \%)$ dan Strata-1 (S1) (35,25\%) dibandingkan dengan tingkat pendidikan tinggi (S2/S3/spesialis) (Tabel 1).

Tabel 1. Karakteristik Sosiodemografi Tenaga Kesehatan ASN di Puskesmas (n=130.931)

\begin{tabular}{lrr}
\hline \multicolumn{1}{c}{ Karakteristik } & $\mathbf{n}$ & $\mathbf{\%}$ \\
\hline Umur (tahun) & & \\
$\quad<38$ & 68.240 & 52,12 \\
$\geq 38$ & 62.691 & 47,88 \\
\hline Jenis Kelamin & & \\
$\quad$ Laki-laki & 22.365 & 17,08 \\
$\quad$ Perempuan & 108.566 & 82,92 \\
\hline Status Pernikahan & & \\
$\quad$ Belum menikah & 7.533 & 5,75 \\
Menikah & 119.532 & 91,29 \\
Cerai hidup & 2.289 & 1,75 \\
Cerai mati & 1.577 & 1,20 \\
\hline Pendidikan terakhir & & \\
DIII & 80.612 & 61,57 \\
S1 & 46.154 & 35,25 \\
S2 & 3.614 & 2,76 \\
Spesialis & 176 & 0,13 \\
S3 & 375 & 0,29 \\
\hline
\end{tabular}

Tabel 2 menunjukkan bahwa sebagian besar tenaga kesehatan ASN yang bekerja di puskesmas merupakan tenaga bidan $(37,72 \%)$ dan perawat $(30,70 \%)$, bekerja $\leq 8$ tahun $(53,70 \%)$, dan akses menuju tempat kerja tergolong mudah $(>90,00 \%)$. Dilihat dari tingkatan motivasi kerja, tenaga kesehatan ASN di puskesmas cenderung memiliki motivasi yang sedang atau cukup $(52,86 \%)$ dan kurang dari seperempatnya memiliki tingkat motivasi yang tinggi $(21,62 \%)$. Hal yang sama juga terlihat pada tingkat kepuasan kerja tenaga ASN yang rata-rata tergolong sedang $(47,42 \%)$, dan lebih dari seperempatnya menyatakan tidak puas dalam bekerja di puskesmas (25,22\%). Meskipun demikian, berdasarkan hasil penilaian terhadap retensi kerja melalui pertanyaan sederhana yaitu betah atau tidak diketahui terdapat lebih dari $90 \%$ tenaga kesehatan ASN yang menyatakan betah dalam bekerja di puskesmas (Tabel 2). 
Tabel 2. Jenis, Motivasi, Kepuasan, dan Retensi Tenaga Kesehatan ASN Bekerja di Puskesmas $(n=130.931)$

\begin{tabular}{|c|c|c|}
\hline Karakteristik & $\mathbf{n}$ & $\%$ \\
\hline \multicolumn{3}{|l|}{ Jenis Tenaga Kesehatan } \\
\hline Dokter Spesialis & 183 & 0,14 \\
\hline Dokter & 9.875 & 7,54 \\
\hline Dokter Gigi & 4.968 & 3,79 \\
\hline Bidan & 49.388 & 37,72 \\
\hline Perawat & 40.201 & 30,70 \\
\hline Farmasi & 4.320 & 3,30 \\
\hline Kesehatan Masyarakat & 6.245 & 4,77 \\
\hline Kesehatan Lingkungan & 4.740 & 3,62 \\
\hline Gizi & 5.202 & 3,97 \\
\hline Keterapian Fisik & 205 & 0,16 \\
\hline Keteknisan Medis & 3.021 & 2,31 \\
\hline Teknis Biomedis & 2.572 & 1,96 \\
\hline Kesehatan Tradisional & 11 & 0,01 \\
\hline \multicolumn{3}{|c|}{ Lama Bekerja di Puskesmas* } \\
\hline$\leq 8$ tahun & 70.314 & 53,70 \\
\hline$>8$ tahun & 60.617 & 46,30 \\
\hline \multicolumn{3}{|c|}{ Akses Menuju Tempat Kerja } \\
\hline Sangat mudah & 37.040 & 28,29 \\
\hline Mudah & 80.844 & 61,75 \\
\hline Sulit & 10.798 & 8,25 \\
\hline Sangat sulit & 2.249 & 1,72 \\
\hline \multicolumn{3}{|l|}{ Motivasi Kerja } \\
\hline Motivasi rendah & 33.418 & 25,52 \\
\hline Motivasi sedang & 69.210 & 52,86 \\
\hline Motivasi tinggi & 28.303 & 21,62 \\
\hline \multicolumn{3}{|l|}{ Kepuasan Kerja } \\
\hline Kepuasan rendah & 33.027 & 25,22 \\
\hline Kepuasan sedang & 62.085 & 47,42 \\
\hline Kepuasan tinggi & 35.819 & 27,36 \\
\hline \multicolumn{3}{|l|}{ Retensi Kerja } \\
\hline Ya, betah & 119.945 & 91,61 \\
\hline Tidak betah & 10.986 & 8,39 \\
\hline
\end{tabular}

Keterangan: * mengacu pada lama bekerja di puskesmas saat ini

Hasil tabulasi silang antara karakteristik, motivasi, dan kepuasan kerja dengan retensi kerja menunjukkan bahwa mayoritas responden yang betah bertugas di puskesmas berada pada kelompok umur lebih dari 38 tahun ke atas (95,11\%) dengan jenis kelamin perempuan (92,09\%), tingkat pendidikan S3 (93,33\%), berstatus cerai mati dengan pasangannya (94,61\%), bekerja di puskesmas lebih dari 8 tahun $(95,69 \%)$ dan memiliki akses ke tempat kerja sangat mudah $(93,94 \%)$. Hasil analisis bivariat dengan uji analisis Chi-Square menunjukkan bahwa terdapat hubungan bermakna $(p<0,05)$ antara umur, jenis kelamin, tingkat pendidikan, status pernikahan, lama bekerja di puskesmas, dan akses menuju tempat kerja dengan motivasi, kepuasan kerja dengan retensi atau kebetahan tenaga kesehatan ASN bekerja di puskesmas $(p<0,05)$, sebagaimana ditunjukkan pada Tabel 3 . 
Tabel 3. Hubungan Karakteristik Sosiodemografi, Motivasi, Kepuasan, dengan Retensi Tenaga Kesehatan ASN di Puskesmas (n=130.931)

\begin{tabular}{|c|c|c|c|}
\hline \multirow{2}{*}{ Variabel } & \multicolumn{2}{|c|}{ Retensi Kerja (n,\%) } & \multirow{2}{*}{$p$} \\
\hline & Ya, Betah & Tidak Betah & \\
\hline Umur (tahun) & & & 0,001 \\
\hline$<38$ & $60.317(88,39)$ & $7.923(11,61)$ & \\
\hline$\geq 38$ & $59.628(95,11)$ & $3.063(4,89)$ & \\
\hline Jenis Kelamin & & & 0,001 \\
\hline Laki-laki & $19.971(89,30)$ & $2.394(10,70)$ & \\
\hline Perempuan & $99.974(92,09)$ & $8.592(7,91)$ & \\
\hline Tingkat Pendidikan & & & 0,001 \\
\hline Rendah (DIII) & $74.182(92,02)$ & $6.430(7,89)$ & \\
\hline Tinggi (S1/S2/S3/Spesialis) & $45.763(90,95$ & $4.556(9,05)$ & \\
\hline Status Pernikahan & & & 0,001 \\
\hline Belum menikah & $6.226(82,65)$ & $1.307(17,35)$ & \\
\hline Menikah & $11.0171(92,17)$ & $9.361(7,83)$ & \\
\hline Cerai & $3.548(91,77)$ & $318(8,23)$ & \\
\hline Lama Bekerja di Puskesmas & & & 0,001 \\
\hline$\leq 8$ tahun & $61.940(88,09)$ & $8.374(11,91)$ & \\
\hline$>8$ tahun & $58.005(95,69)$ & $2.612(4,31)$ & \\
\hline Akses Menuju Tempat Kerja & & & 0,001 \\
\hline Mudah & $109.998(93,31)$ & $7.886(6,69)$ & \\
\hline Sulit & $9.947(76,24)$ & $3.100(8,4)$ & \\
\hline Motivasi Kerja & & & 0,001 \\
\hline Motivasi rendah & $27765(83,08)$ & $5653(16,92)$ & \\
\hline Motivasi sedang & $64895(93,77)$ & $4315(6,23)$ & \\
\hline Motivasi tinggi & $27285(96,40)$ & $1018(3,60)$ & \\
\hline Kepuasan Kerja & & & 0,001 \\
\hline Kepuasan rendah & $27010(81,78)$ & $6017(18,22)$ & \\
\hline Kepuasan sedang & $58118(93,61)$ & $3967(6,39)$ & \\
\hline Kepuasan tinggi & $34817(97,20)$ & $1002(2,80)$ & \\
\hline
\end{tabular}


Hasil multivariat memperlihatkan bahwa tenaga kesehatan dengan status menikah memiliki pengaruh 1,5 kali untuk retensi bekerja di puskesmas (OR=1,550; 95\%CI: 1,4691,635), sementara itu status bercerai, baik cerai mati maupun hidup memiliki pengaruh 1,2 kali (OR=1,261; 95\%CI: 1,153-1,379) (Tabel 4). Masa tugas di puskesmas lebih dari 8 tahun memiliki pengaruh 1,3 kali terhadap retensi kerja (OR=1,337; 95\%CI: 1,300-1,376). Kemudahan akses menuju puskesmas memiliki pengaruh 1,9 kali untuk mengalami retensi kerja $(\mathrm{OR}=1,928$;
95\%CI: 1,848-2,011). Kemudahan akses menjadi faktor yang paling mempengaruhi retensi tenaga kesehatan. Tingkat pendidikan, umur, jenis kelamin diketahui menjadi faktor yang berpengaruh terhadap retensi kerja namun tidak terlalu memberikan efek yang besar $(\mathrm{OR}=1,1)$. Berdasarkan Tabel 4 juga diketahui pula bahwa kepuasan kerja yang tinggi berpengaruh 1,3 kali menjadikan retensi tenaga kesehatan untuk kerja di puskesmas (OR=1,319; 95\%CI: 1,269-1,370) sementara itu motivasi kerja merupakan faktor protektif terhadap retensi kerja $(\mathrm{OR}<1)$.

Tabel 4. Analisis Multivariat

\begin{tabular}{|c|c|c|c|}
\hline Variabel & $\mathbf{O R}_{\text {adjusted }}$ & $95 \% \mathrm{CI}$ & $p$ \\
\hline \multicolumn{4}{|l|}{ Umur (tahun) } \\
\hline$<38$ & 1 & & 0,001 \\
\hline$\geq 38$ & 1,131 & $1,099-1,164$ & \\
\hline \multicolumn{4}{|l|}{ Jenis Kelamin } \\
\hline Laki-laki & 1 & & 0,001 \\
\hline Perempuan & 1,168 & $1,129-1,209$ & \\
\hline \multicolumn{4}{|l|}{ Tingkat Pendidikan } \\
\hline Rendah (DIII) & 1 & & 0,001 \\
\hline Tinggi (S1/S2/S3/Spesialis) & 1,129 & $1,100-1,160$ & \\
\hline \multicolumn{4}{|l|}{ Status Pernikahan } \\
\hline Belum menikah & 1 & & \\
\hline Menikah & 1,550 & $1,469-1,635$ & 0,001 \\
\hline Cerai & 1,261 & $1,153-1,379$ & 0,001 \\
\hline \multicolumn{4}{|l|}{ Lama Bekerja di Puskesmas } \\
\hline$\leq 8$ tahun & 1 & & 0,001 \\
\hline$>8$ tahun & 1,337 & $1,300-1,376$ & \\
\hline \multicolumn{4}{|l|}{ Akses Menuju Tempat Kerja } \\
\hline Sulit & 1 & & 0,001 \\
\hline Mudah & 1,928 & $1,848-2,011$ & \\
\hline \multicolumn{4}{|l|}{ Motivasi Kerja } \\
\hline Motivasi rendah & 1 & & \\
\hline Motivasi sedang & 0,972 & $0,942-1,004$ & 0,09 \\
\hline Motivasi tinggi & 0,907 & $0,871-0,944$ & 0,00 \\
\hline \multicolumn{4}{|l|}{ Kepuasan Kerja } \\
\hline Kepuasan rendah & 1 & & \\
\hline Kepuasan sedang & 1,087 & $1,052-1,123$ & 0,001 \\
\hline Kepuasan tinggi & 1,319 & $1,269-1,370$ & 0,001 \\
\hline
\end{tabular}




\section{PEMBAHASAN}

Hasil penelitian menunjukkan bahwa sebanyak 91,61\% tenaga kesehatan merasa betah di puskesmas tempat kerjanya. Seorang pegawai akan merasa betah dalam suatu organisasi disebabkan diantaranya karena telah beradaptasi dengan lingkungan yang cukup lama sehingga merasa nyaman dengan tempat

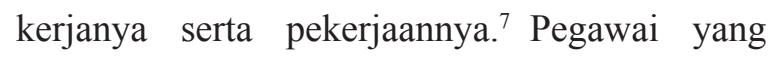
betah di tempat kerjanya cenderung untuk tidak akan meninggalkan tempat kerjanya. Menurut Waldman, ${ }^{8}$ retensi tenaga kerja merupakan waktu antara awal kerja dan berakhirnya atau meninggalkan pekerjaan, ukurannya adalah masa kerja. Retensi dapat disebabkan faktor personal ataupun lingkungan kerja. ${ }^{4}$ Perpindahan tenaga kesehatan dapat berdampak serius dalam penyediaan sumber daya manusia di puskesmas karena dapat memperburuk keseimbangan tenaga kesehatan di wilayah tersebut.

Hasil studi menunjukkan bahwa variabel umur, jenis kelamin, tingkat pendidikan, status pernikahan, lama bekerja, akses menuju tempat kerja, motivasi, dan kepuasan kerja mempengaruhi tenaga kesehatan untuk betah bekerja di puskesmas. Hasil penelitian lain menyebutkan bahwa tenaga kesehatan di negaranegara berkembang memutuskan untuk pindah dikarenakan gaji yang kurang, motivasi rendah dan ketidakpuasan serta skeptisme yang terus berkembang. Peningkatan upah serta kondisi lingkungan kerja merupakan faktor insentif untuk betah di tempat kerjanya. Selain itu, hal lain yang juga penting adalah peningkatan pensiun, perawatan anak, peluang pendidikan dan pengakuan. ${ }^{9}$ Hasil dari studi ini sesuai dengan penelitian lain yang menyatakan bahwa terdapat hubungan antara motivasi, kepuasan kerja, dengan perpindahan kerja tenaga kesehatan. ${ }^{10}$

Motivasi merupakan hal yang sangat penting yang dapat mempengaruhi perilaku dan kinerja dari tenaga kesehatan. Motivasi petugas kesehatan adalah penentu utama retensi tenaga kesehatan dan kinerja sektor kesehatan. ${ }^{11}$ Berdasarkan hasil analisis bivariat diperoleh nilai OR sebesar 0,972 untuk motivasi sedang dan 0,907 untuk motivasi tinggi (nilai OR $<1$ ). Hal ini menunjukkan bahwa motivasi sedang dan motivasi tinggi merupakan faktor protektif terhadap retensi kerja tenaga kesehatan. Hal ini sesuai dengan hasil sistematik review tentang faktor-faktor yang mempengaruhi retensi yang menyatakan bahwa motivasi mempengaruhi retensi tenaga kesehatan. ${ }^{11}$ Studi lain menyebutkan bahwa motivasi kerja dan retensi karyawan memiliki pengaruh positif. Karyawan bersemangat atau memiliki motivasi tinggi terhadap apa yang dikerjakan membuat karyawan tersebut ingin terus bertahan (retensi) dan loyal terhadap pekerjaannya. ${ }^{12}$

Untuk meningkatkan motivasi tenaga kesehatan perlu memperkuatkapasitas manajemen dalam pelayanan kesehatan. Beberapa aspek yang terkait seperti kompetensi manajemen, dukungan sosial di tempat kerja, perlakuan yang adil terhadap karyawan serta pengawasan dan penilaian kinerja. ${ }^{13,14}$ Oleh karena itu pihak pemberi kerja dituntut dapat menciptakan kondisi kerja yang kondusif bagi pekerja dan para atasan juga dituntut dapat memberikan motivasi kerja terhadap para pekerja. ${ }^{14}$

Robbins menyatakan kepuasan kerja mengacu kepada perasaan seseorang terhadap pekerjaannya. Seseorang dengan kepuasan kerja yang lebih tinggi menjaga perasaan positif ke arah pekerjaan. Sebaliknya, seseorang atau siapapun yang tidak puas memiliki perasaan negatif terhadap pekerjaannya. Robbins juga menyebutkan bahwa pada konteks pekerjaan, tentunya bila upah yang diterima adil sesuai dengan tuntutan pekerjaan, tingkat keterampilan individu, dan standar pengupahan komunitas, 
kemungkinan besar dihasilkan kepuasan dan memiliki niat (intention) yang lebih tinggi untuk bertahan dalam pekerjaan. ${ }^{15}$ Di lain pihak, Baron ${ }^{14}$ menyatakan bahwa lingkungan kerja juga akan menentukan karyawan tersebut masih mau bertahan dalam pekerjaan atau tidak. Hasil penelitian ini menunjukkan bahwa terdapat hubungan antara kepuasan kerja dengan retensi tenaga kesehatan. Kepuasan kerja yang tinggi berpengaruh 1,3 kali menjadikan retensi tenaga kesehatan untuk bekerja di puskesmas $(\mathrm{OR}=1,319 ; 95 \% \mathrm{CI}: 1,269-1,370)$. Hal ini sejalan dengan studi lain yang menyatakan bahwa faktor kepuasan kerja berhubungan dengan psikologi seseorang terkait diri dan perilaku mereka yang mempengaruhi retensi karyawan (77,50\%), sedangkan sisanya $(22,50 \%)$ dipengaruhi oleh faktor lain seperti faktor psikologi atau faktor motivasi. $^{2}$ Pada penelitian lain ditemukan bahwa petugas kesehatan yang tidak puas dengan pekerjaannya cenderung untuk berniat meninggalkan jabatannya. Ketidakpuasan kerja tersebut dipengaruhi oleh kondisi hidup dan kerja yang tidak memadai, remunerasi keuangan yang tidak konsisten, dan sistem pendukung pelayanan kesehatan yang buruk. $^{20}$ Hasil penelitian di Lebanon mengungkapkan adanya hubungan proporsional secara langsung antara kepuasan kerja perawat yang dilaporkan dan niat mereka untuk tinggal. ${ }^{21}$

Undang-undang Nomor 36/2009 pasal 21 menyatakan bahwa "pemerintah mengatur perencanaan, pengadaan, pendayagunaan, pembinaan, dan pengawasan mutu tenaga kesehatan dalam rangka penyelenggaraan pelayanan kesehatan melalui Peraturan Pemerintah". ${ }^{22}$ Oleh karena itu dalam upaya pendayagunaan tenaga kesehatan, pemerintah tidak hanya mengatur tentang pendistribusian, pemanfaatan, dan pengembangannya saja, namun juga perlu mengatur bagaimana dapat mempertahankan keberadaan tenaga kesehatan di tempat tugasnya. Menjaga tenaga kesehatan untuk betah bekerja di tempat kerjanya memerlukan komitmen dari berbagai pihak. Perlu upaya perbaikan terhadap faktor-faktor yang mempengaruhi retensi dari tenaga kesehatan. Dalam penelitian ini variabel terkait karakteristik tenaga kesehatan yang diukur adalah umur, jenis kelamin, tingkat pendidikan, status pernikahan, lama bekerja di puskesmas dan akses menuju tempat kerja.

Hasil penelitian menunjukkan bahwa keenam variabel tersebut kesemuanya berhubungan dengan retensi $(p=0,000 ;$ OR $>1)$ dan faktor dominan yang berhubungan diantara semuanya adalah akses menuju tempat kerja $(\mathrm{OR}=1,928 ; \quad 95 \% \mathrm{CI}: \quad 1,848-2,011)$. Faktor terkait akses menuju tempat kerja meliputi kemudahan transportasi serta keterjangkauan tempat kerja dari tempat tinggalnya. Prespektif yang dihasilkan dari studi ini memperlihatkan salah satu upaya dalam mempertahankan tenaga kesehatan di tempat kerjanya. Bagi pekerja, kesejahteraan dalam berkarir dapat dipengaruhi oleh banyak hal, salah satunya ialah kenyamanan mobilisasi. Perjalanan menuju dan kembali dari tempat kerja bisa dikatakan memiliki pengaruh besar dalam menentukan suasana hati dan produktivitas. Karenanya, jarak antara tempat tinggal dan tempat kerja menjadi suatu hal yang penting dipertimbangkan. Hal ini sesuai dengan penelitian di Zambia yang menyebutkan bahwa faktor lain yang banyak dikeluhkan oleh tenaga kesehatan adalah kurangnya transportasi ke dan dari klinik tempat kerja, selain juga kekurangan tenaga. ${ }^{23}$ Beberapa orang memilih untuk tinggal dekat dengan tempat kerja karena memberi keuntungan tersendiri, mulai dari segi ekonomi hingga sosial. Jarak tempuh yang lebih dekat bahkan tidak membutuhkan transportasi atau tempat tinggal masih dalam radius berjalan kaki 
akan sangat menguntungkan terlebih bagi tenaga kesehatan. Pasien bisa datang kapan saja terutama saat keadaan darurat. Pasien di daerah terpencil dimana jarak ke fasilitas pelayanan kesehatan (fasyankes) jauh, sangat membutuhkan kesiagaan tenaga kesehatan 24 jam. Tinggal berdekatan dengan tempat kerja juga memungkinkan tenaga kesehatan untuk memiliki jadwal yang lebih fleksibel. Pasien yang datang mendadak mungkin tak akan membuat tenaga kesehatan kelabakan, karena perjalanan dari rumah ke tempat kerja tidak menyita waktu dan tenaga. Kebijakan pemerintah daerah dengan penempatan tenaga kesehatan tinggal dekat dengan puskesmas di rumah dinas menjadi hal yang dapat mengurangi jumlah pergantian tenaga kesehatan, terutama di daerah terpencil. Hasil penelitian di Australia menyebutkan bahwa pelayanan kesehatan primer di daerah terpencil dengan akses yang sulit mengalami penggantian pegawai yang sangat tinggi sehingga banyak memakai staf sementara. ${ }^{24}$ Beberapa daerah membuat kebijakan pembangunan rumah dinas bagi tenaga kesehatan di puskesmas agar dapat fokus bertugas, dengan harapan supaya tenaga kesehatan tinggal dekat puskesmas dapat cepat datang ketika dibutuhkan. Suasana kerja yang nyaman diharapkan dapat membuat tenaga kesehatan betah dan bersedia terus menetap di daerah tersebut. Hal tersebut juga terlihat dalam penelitian lain yang menunjukkan hasil bahwa keterpencilan, sulitnya akses transportasi serta kondisi kerja yang tidak mendukung menjadi faktor yang mendorong perawat di Jordania untuk bermigrasi dan bekerja ke luar negeri. ${ }^{25}$

\section{KESIMPULAN}

Berdasarkan hasil penelitian, maka dapat disimpulkan bahwa umur, jenis kelamin, tingkat pendidikan, status pernikahan, lama bekerja di puskesmas, akses menuju tempat kerja, motivasi, dan kepuasan kerja secara statistik berhubungan dengan retensi atau kebetahan tenaga kesehatan ASN untuk terus bekerja di puskesmas $(p<0,05)$. Hasil analisis multivariat diketahui faktor dominan yang berhubungan dengan retensi ASN adalah akses menuju tempat kerja $(\mathrm{OR}=1,928 ; 95 \% \mathrm{CI}$ : 1,848-2,011). Kemudahan akses ke tempat kerja sangat diperlukan bagi tenaga kesehatan dalam upaya pelayanan kesehatan yang selalu siap sedia bagi masyarakat di puskesmas.

\section{SARAN}

Retensi merupakan isu kompleks yang memerlukan pendekatan dari berbagai sektor. Kerjasama lintas sektor merupakan strategi retensi yang efektif dengan tidak hanya memperhatikan tenaga kesehatannya saja tetapi juga lingkungan sekitar. Upaya lintas sektoral baik dari pemerintah baik pusat maupun daerah dalam upaya mempertahankan tenaga kesehatan bekerja di daerah dengan cara memudahkan akses tenaga kesehatan ke tempat kerja. Kemudahan akses ke tempat kerja bisa dilakukan melalui pembangunan akses ke puskesmas ataupun kemudahan transportasi. Selain itu pemerintah daerah dapat memberikan kemudahan bagi tenaga kesehatan dengan menempatkan tenaga kesehatan di rumah dinas dekat dengan puskesmas.

\section{UCAPAN TERIMA KASIH}

Penulis berterima kasih kepada Badan Litbangkes, Kementerian Kesehatan yang mengizinkan penggunaan karya berharganya yakni Riset Ketenagaan di Bidang Kesehatan (Risnakes) tahun 2017. 


\section{DAFTAR PUSTAKA}

1. World Health Organization. Global Strategy on Human Resources for Health: Workforce 2030. WHO [Internet]. 2016;64. Available from: http://www.who.int/workforcealliance/ media/news/2014/consultation_globstrat_ hrh/en/\%0Ahttp://apps.who.int/iris/bitstre am/10665/250368/1/9789241511131-eng. pdf?ua $=1 \% 5$ Cnhttp://www.who.int/hrh/ resources/pub_globstrathrh-2030/en/

2. Yadi H. Motivasi dan Retensi Tenaga Kesehatan di Asia Tenggara (Indonesia, Belajar dari Negara Pembanding). Prosiding SNaPP2017 Kesehatan. 2017;3(1):135-143

3. Efendi F, Kurniati A. Review Sistematis Peningkatan Retensi Tenaga Kesehatan di Daerah Tertinggal. Surabaya; Fakultas Kesehatan Masyarakat Universitas Airlangga; 2012

4. Kementerian Kesehatan RI. Dokumen Rencana Kebutuhan SDM Kesehatan Tahun 2018. Jakarta: Kementerian Kesehatan RI; 2018.

5. Labarda MP. Career Shift Phenomenon among Doctors in Tacloban City, Philippines: Lessons for Retention of Health Workers in Developing Countries. Asia Pac Fam Med. 2011;10(1):13.

6. Kementerian Kesehatan RI. Laporan Riset Ketenagaan di Bidang Kesehatan Rumah Sakit. Jakarta : Kementerian Kesehatan RI; 2018.

7. Fitriyanti, Tasnim. Faktor Faktor yang Berhubungan dengan Kompetensi Tenaga Administrasi di Rumah Sakit Umum Bahteramas. J MJPH. 2018;1(2).

8. Waldman J. Change your Metrics: If You Get What You Measure, then Measure What You Want - Retention. J Med Pract Manage. 2006;22(1):1319.

9. Zurn P, Dal Poz MR, Stilwell B, Adams O. Imbalance in the Health Workforce. Hum Resour Health. 2004;2:1-12.

10. Bonenberger M, Aikins M, Akweongo P, Wyss
K. The Effects of Health Worker Motivation and Job Satisfaction on Turnover Intention in Ghana : a Cross-Sectional Study. Hum Resour Health. 2014;1-12.

11. Peters DH, Chakraborty S, Mahapatra P, Steinhardt L. Job Satisfaction and Motivation of Health Workers in Public and Private Sectors: Cross-sectional Analysis from Two Indian States. Hum Resour Health. 2010;8:1-11.

12. Nguyen THT, Wilson A, McDonald F. Motivation or Demotivation of Health Workers Providing Maternal Health Services in Rural Areas in Vietnam: Findings from a Mixed-methods Study. Hum Resour Health [Internet]. 2015;13(1):111. Available from: http://dx.doi.org/10.1186/ s12960-015-0092-5

13. Lai GC, Taylor EV, Haigh MM, Thompson SC. Factors Affecting the Retention of Indigenous Australians in the Health Workforce: A Systematic Review. Int $\mathrm{J}$ Environ Res Public Health. 2018;15(5).

14. Permata PR, Rahardja E. Analisis Pengaruh Sistem Reward, Motivasi Kerja, dan Komitmen Organisasional terhadap Retensi Karyawan. Diponegoro Journal of Management 2016;5:1-11.

15. Robbins, SP. Perilaku Organisasi, Edisi Kesepuluh. Jakarta: Gramedia; 2006.

16. Daneshkohan A, Zarei E, Mansouri T, Maajani K, Ghasemi MS, Rezaeian M. Factors Affecting Job Motivation among Health Workers: a Study from Iran. Glob J Health Sci. 2015;7(3):153-60.

17. Mutale W, Ayles H, Bond V, Mwanamwenge MT, Balabanova D. Measuring Health Workers' Motivation in Rural Health Facilities: Baseline Results from Three Study Districts in Zambia. Hum Resour Health. 2013;11(1):1-8.

18. Ripaldi AMR. Pengaruh Kepuasan Kerja dan Organizational Citizenship Behavior Terhadap Stres Kerja dan Retensi Karyawan di PT Multi Auto Intrawahana Pekanbaru. J Online Mhs Fak Ekon Univ Riau. 2016;4(1):518-32. 
19. Seran I, Giri E, Ndoen LM. Pengaruh Kepuasan dan Lingkungan Kerja terhadap Retensi Karyawan (Studi Kasus pada PT. Surya Bataramah Kota Kupang). J Bisnis Manaj. 2018:10(1):44 - 57.

20. Narayan V, John-Stewart G, Gage G, O’Malley G. If I had Known, I Would Have Applied: Poor Communication, Job Dissatisfaction, and Attrition of Rural Health Workers in Sierra Leone. Hum Resour Health. 2018;16(1):1-12.

21. El-Jardali F, Alameddine M, Jamal D, Dimassi H, Dumit NY, McEwen MK, et al. A National Study on Nurses' Retention in Healthcare Facilities in Underserved areas in Lebanon. Hum Resour Health [Internet]. 2013;11(1):1.

22. Republik Indonesia. Undang Undang Republik Indonesia Nomor 36 Tahun 2009 Tentang Kesehatan. Jakarta; 2009.
23. Cross SS, Baernholdt M. Identifying Factors for Worker Motivation in Zambia's Rural Health Facilities. J Health Care Poor Underserved. 2017;28(1):63-70.

24. Russell DJ, Zhao Y, Guthridge S, Ramjan M, Jones MP, Humphreys JS, et al. Patterns of Resident Health Workforce Turnover and Retention in Remote Communities of the Northern Territory of Australia, 2013-2015. Hum Resour Health. 2017;15(1):1-13.

25. AbuAlRub RF, El-Jardali F, Jamal D, Iblasi AS, Murray SF. The Challenges of Working in Underserved Areas: A Qualitative Exploratory Study of Views of Policy Makers and Professionals. Int J Nurs Stud. 2013; 50(1):73-82. 